\section{Human leucocyte antigens (HLA) in neonates with an inadequate response to hepatitis $B$ vaccination}

Inadequate responses to hepatitis $\mathbf{B}$ vaccine occur in approximately $5-15 \%$ of neonates. Factors that influence the response to vaccination include the immunogenetic state of the vaccine recipient: carriers of the human leucocyte antigen (HLA)-B8, DR3 do not develop adequate responses to hepatitis $B$ vaccine $^{1}$. To determine the importance of the immunogenetic factor for the outcome of hepatitis $B$ vaccination in neonates, we investigated the HLA type of infants with an inadequate response to hepatitis $B$ vaccination and analysed the subgroups non-infected low responders and infected non-responders for differences in the specific HLA type.

Between 1982 and 1991, 705 healthy newborns from $\mathrm{HBsAg}$-positive mothers received $\mathrm{HBIg}$ at birth and were vaccinated within the first year with plasma or recombinant-DNA vaccine according to a three- or four-dose vaccination schedule ${ }^{2}$. During the first year blood was assayed for $\mathrm{HBsAg}$ and anti-HBs (IU/1) at 3, 6,11 and 12 months of age. Sixteen of the 705 newborns $(2.3 \%)$ with anti-HBs titres $<10 \mathrm{IU} / 1$ were identified; eight infants with an anti-HBs level below $10 \mathrm{IU} / 1$ and negative tests for HBsAg (non-infected low responders ) and another eight infants who became anti-HBs negative but HBsAg-positive (infected non-responders).

HLA typing for class I and II antigens was performed, using standard microcytotoxicity test on peripheral blood mononuclear cells.

Table 1 shows the HLA phenotypes of the eight non-infected low responders and
Table 1 HLA type for eight non-infected low responders and eight infected non-responders to hepatitis $B$ vaccine

\begin{tabular}{|c|c|c|c|c|c|}
\hline \multirow[b]{2}{*}{ Group } & \multirow{2}{*}{$\begin{array}{l}\text { Ethnic } \\
\text { background }^{a}\end{array}$} & \multicolumn{4}{|c|}{ HLA type } \\
\hline & & $\mathrm{B}$ & & DR & \\
\hline \multicolumn{6}{|c|}{ Non-infected low responders } \\
\hline 1 & Medit. & 7 & 8 & 3 & - \\
\hline 2 & Neth. & 62 & 18 & 3 & - \\
\hline 3 & Medit. & 13 & 35 & 1 & 3 \\
\hline 4 & Neth. & 8 & 56 & 1 & 3 \\
\hline 5 & Medit. & 18 & 35 & 4 & - \\
\hline 6 & Medit. & 35 & 53 & - & 11 \\
\hline 7 & Cap. V. & 58 & - & 13 & 11 \\
\hline 8 & Medit. & 60 & 72 & 13 & 15 \\
\hline \multicolumn{6}{|c|}{ Infected non-responders } \\
\hline $1^{b}$ & Medit. & 18 & 48 & 4 & 14 \\
\hline $2^{b}$ & Medit. & 18 & 48 & 4 & 14 \\
\hline 3 & Medit. & 49 & 35 & 7 & - \\
\hline 4 & Medit. & 35 & 37 & 11 & - \\
\hline 5 & Medit. & 35 & - & 11 & 8 \\
\hline 6 & Asia & 58 & - & 15 & 13 \\
\hline 7 & Medit. & 52 & 63 & 15 & 7 \\
\hline 8 & Asia & 55 & 61 & 11 & 13 \\
\hline
\end{tabular}

-, Possibly homozygous

${ }^{a}$ Ethnic background: Mediterranean, The Netherlands, Cape Verde Islands, Asia. A rough estimate of expected DR3 homozygotes in this ethnic group is $1-2 \%$

${ }^{b}$ Infected non-responders 1 and 2 are brother and sister the eight infected non-responders to hepatitis $B$ vaccine. HLA-DR3 was present in four of the eight $(50 \% ; 95 \%$ $\mathrm{CI}: 15-85 \%$ ) non-infected low responders and in none of the eight $(0 \%)$ infected non-responders. Two non-infected low responders were probably homozygous for HLA-DR3.

This study confirms that the HLADR3 haplotype plays a role in the low responsiveness to hepatitis $\mathbf{B}$ vaccination in non-infected neonates. In our study with only a small number of ethnically heterozygous individuals, all four DR3positive children were non-infected low responders and two of them were probably homozygous for DR3. These low responders were not absolute non-responders, since all of them developed protective anti-HBs levels after hepatitis $\mathbf{B}$ revaccination in their second year of life ${ }^{3}$. The two children homozygous for HLA-DR 3 produced anti-HBs in the lowest range (45 and $55 \mathrm{IU} / 1$, respectively) after revaccination in comparison to the other six revaccinated low responders (median 171, range 49-3497 IU/1). The observation that none of the eight non-responders, who became infected with hepatitis B virus, was DR3-positive suggests that HLAassociated low responsiveness is not causally related to this type of failure of hepatitis $B$ vaccination.

R. del Canho* R.R.P. de Vries ${ }^{\dagger}$ and S.W. Schalm*

* Department of Internal Medicine II, University Hospital Dijkzigt, Rotterdam, The Netherlands.

${ }^{\dagger}$ Department of Immunohaematology and Blood Bank, University Hospital, Leiden, The Netherlands

\section{REFERENCES}

1 Alper, C.A., Kruskall, M.S., Marcus-Bagley, D. Craven, D.E., Katz, A.J. Brink, S.J. et al Genetic prediction of nonresponse to hepatitis B vaccine. N. Engl. J. Med. 1989, 321, 708-712

2 Schalm, S.W., Mazel, J.A., de Gast, G.C., Heijtink R.A Botman, MJ Bänffer, JRJ et al. Prevention of hepatitis $B$ infection in newborns through mass screening and delayed vaccination of all infants of mothers with hepatitis B surface antigen. Pediatrics 1989,83 , 1041-1048

3 del Canho, R. Schalm, S.W and Heijtink, R.A Hepatitis $B$ revaccination of neonates with inadequate response after primovaccination. Vaccine 1992, 10,69 